the internal surface of the ilium. Corresponding to the acetabulum, in the anterior aspect of the upper third of the thigh, were three or four fistulous openings of superficial burrowing abscesses; while posteriorly the skin had sloughed away, so as to leave a ragged quadrilateral opening, through which projected the trochanter, covered by its muscles. The limb itself was straight, not inverted, and only slightly shortened; and $\mathrm{Mr}$. Wood said that he had hoped at first that good diet and nursing rould save the child from an operation, but that interference had now become necessary to save life. He added that disease of the hip is one which, in most instances, has a tendency to cure itself, and that when an operation is resorted to, it is generally to remedy distortion, and to basten the natural process of healing; but in this case there was little distortion to rectify, and the operation was required to give the child a chance of life by removing diseased structures, and affording a free exit for discharges. Having removed a considerable quantity of diseased bone, Mr. Wood said that he had found a perforation of the acetabulum communicating with the pelvic abscess, and caries of the head, neck, and part of the shaft of the bone. In the latter situation he had removed the diseased tissue by gouging down the shaft to the extent of about an inch, leaving a thin shell covered by the periosteum. It was his habit also to remove the trochanter in these cases, even if proved to be healthy; for both $\mathrm{Sir}^{2}$ Wm. Fergusson and himself had found that the resulting limb was none the better for a literal adherence to the principles of conservative surgery in this respect; while, on the other hand, if the trochanter were left, the operator had to work round and beneath it, making a much larger wound, at the mouth of which he left an effective obstruction to the free discharge of matter and spicula of bone. But he was most careful at this point, and at every other which he touched in the operation, to save the perichondrium and periosteum; especially he preserved the perichondrium of the trochanter and the attuchments of its muscles, leaving a well-defined cartilaginous arch, from beneath which he removed the diseased bone. Mr. Wood explained that this operation was known and practised elsewhere; but that the part which he claimed was the removal piecemeal, instead of en masse, of the diseased bone, and that by this proceeding he saved the largest possible surface of bone-producing tissue; also that the extermal wound, the internal damage to soft parts, and hæmorrhage were reduced, and that the recovery was more rapid. The general result of the operation, as a whole, was said to be the formation of a smooth, rounded head on the upper extremity of the femur, which does not become anchylosed with, but moves freely in, the acetabulum. Mr. Wood also drew attention to his having commenced the operation by making a T-shaped incision, the tail portion of which he always endeavours to bring over the spot where he would be likely to use the saw, which he could then freely handle without further injury to the skin; while after the operation there remained a depending furrow, which facilitated the evacuation of discharges.

\section{MIDDLESEX HOSPITAL.}

EXCISION OF A FIBROUS TUROUR ATTACHED TO THE FXSCIA TRANSVERSALIS. - TAPPING FOR ASCTTES.

(Under the care of Mr. Hurke.)

AUG. כтH.-The patient, a woman rather below middle age, presented an oval tumour situated above the outer two-thirds of the crural arch of the right side. Mrr. Hulke said a difference of opinion existed among his colleagues as to whether the tumour was within or external to the peritoneum. Its upper two-thirds were freely movable; the lower third was attached. That it was not in relation with the uterus had been ascertained by deflecting that organ by means of a sound. He proposed to make a free incision through the superficial structures, to dissect cautiously down towards the tumour, and to remove it, unless he found it impossible to do so without injury to the peritoneum. Accordingly, having dirided the superficial tissues, Mr. Hulke dissected through the external and internal oblique and the superficial portion of the transversalis, and found the tumour to be attached to the fascia transversalis. By very cautious dissection, mainly with the handle of the scalpel and the finger, it was remored without injury to any deeper structures. The wound, having been closed with a couple of sutures dipped in carbolic lotion, was dressed, according to Professor Lister's method, with carbolic oilskin, lac, and strapping. The patient was ordered a grain of opium immediately on recovering consciousness, and one every subsequent three hours. The tumour was a simple fibrous growth, about half as large again as a hen's egg. Mr. Hulke has given the system of carbolic-acid dressing a long and varied trial, and speaks very highly of it as a mode of dressing the wound producel by paracentesis abdominis.

We afterwards saw Mr. Hulke tap a patient for ascites. The way in which it is his habit to dress the wound in the skin which has been produced by a preliminary touch with a knife, is as follows:-The lips of the small wound are transfixed by a needle, beneath which a suture is wound in a simple circular direction, a small square of lint is placed underneath on either side, and the ends of the needle are clipped off in the usual way; over the whole is then laid a thin layer of cotton wool dipped in collodion, and a little of this latter is added to ensure the cotton wool and lint being cemented together into a contracting shield, which is both air-tight and water-tight.

\section{BELGRAVE CHILDREN'S HOSPITAL.}

CASE OF HYDATIDS OF THE LIVER.

(Under the care of Dr. Anstit.)

AgNes B-, aged six years, was admitted into this hospital on May 3rd. About two months ago, while on the voyage home from Australia, where she was born, the mother noticed a swelling just beneath the ribs, on the right side, which gradually increased in size, and at the time of the child's admission formed a fluctuating tumour extending from the lower border of the last floating rib to the umbilicus in one direction, and to a point midway between the last rib and the crest of the ilium in the other. The child, when measured just below the ribs, was found to be about twenty-seven inches round. She did not complain of any pain, except when pressure was made on the tumour. When six months old she had dysentery, but has never had any other illness. She was ordered bark and iodide of potassium, and was kept in bed. This treatment was continued till the $18 \mathrm{th}$, when the tumour was found to have increased in size, and to have become more painful. A grooved needle was passed in by Mr. T. Pick, and some clear fluid escaped. A very fine trocar was immediately afterwards introduced, and about seven ounces of fluid drawn off. It was alkaline and non-albuminous; no hooklets were discovered in it under the microscope, only a number of crystals of various forms, all more or less coloured green. The cyst was not emptied.

The child passed a restless night after the tapping, and the next day the temperature had risen, and there was a little fever. This, howerer, passed off in a day or two. After the fluid was removed, the child only measured twenty-four inches. She continued this size till June the 8th, when she measured twenty-five inches. On the 18th she got up, and gradually diminished in size from that time. After being up a week she only measured twenty-two inches. She sad no pain; her bowels were regular (when first admitted they were rather constipated). Percussion was quite resonant over the region formerly occupied by the tumour.

Nothing occurred to raise a doubt that the cure was complete until about the Jth of July, when it was noticed that the abdomen was slowly increasing in size. On the 8th it was found to measure twenty-three inches, or one inch more than it had previously sunk to.

On July 12th Dr. Anstie made a careful examination. There could be no doubt that the region of dulness on percussion had extended downwards somewhat, and the superficial appearance was as if the liver had re-enlarged. Careful palpation and percussion, however, induced considerable doubt of this. It was found on inquiry that the child had suffered much from flatulence, and that the motions were light-coloured. The appetite was good enough; but it was distinctly made out that potatoes regularly produced indigestion and "rumbling with wind." Accordingly cabbage was ordered to be given with dinner instead of potatoes, and 
the child was ordered to take small doses of dilute nitric and muriatic acids, with gentian. The result was that the digestive discomfort immediately disappeared; and on reexamining the abdomen on July 19th, a week later, the size round was again only twenty-two inches, and there was clearpercussion over the whole region formerly occupied by the turscur. The child was now looking exceedingly well and healtry, and a few days later was discharged perfectly cured.

The above notes were kindly supplied by Mr. W. Macdonald, the house-surgeon, and Dr. Anstie has added the following comments :-

This case has nothing remarkable in its features now that the story is all told; it is only a confirmation of the fact-still far too little popularised-that early puncture of a hydatid tumour with a fine trocar, and withdrawal of a portion of the fluid, is in itself quite innocuous, and is practically the only treatment worthy of a moment's consideration. There was, however, some little difference of opinion as to the diagnosis in the first instance. It had been discovered that the child had suffered from dysentery when in Australia, and it was suggested that the tumour might be a chronic abscess, secondarily produced. In favour of this view it was urged that the tumour did not present the welldefined and globular shape which is usually characteristic of hydatids. Dr. Anstie declined to accept the theory of abscess, chiefly because of the very considerable time (twelve months) which had elapsed between the attack of dysentery and the first notice of the swelling; of the total absence of any history of severe pain or shivering at any part of the intervening period; and of the appearance of excellent health and spirits which the child presented. Still, without the aid of the exploration-needle, or the fine trocar, there might have been a certain amount of hesitation in tapping. With the fine trocar in our hands it is not too much to say that we may venture to tap any tumour that can possibly exist, with at least the certainty that we shall do no harm; and, in case it turns out to be hydatids which have not existed too long, with the certainty of speedy cure.

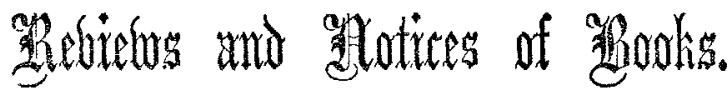

First Revort of the Gas Referees to the Board of Trade. The Sulphur Question. Official Return. July, 1870. (CONCLUDING NOTICE.)

THe establishment of a Board of Referees was an indispensable concomitant of the Gas Act of 1868, as a means of carrying out impartially the most important provisions of that Act, and also as a tribunal for investigating and solving questions connected with gas manufacture, which Parliament, after hearing both sides of the case, felt itself incompetent to decide. But for the establishment of such a Board, holding a neutral and impartial position, the Acts of 1868-69 would have proved as unworkable as the Act of 1860. The gas companies would have been in a state of chronic mutiny, or the public agitation would have continued as violent as before. The fact that there is no threat of renewed fight on the part of the companies, and no complaint on the part of the public - a state of matters hitherto unheard of,-is a remarkable proof of the confidence which both of the old belligerent parties place in the impartiality and care with which the duties of this Board are discharged.

Apart from their ordinary and permanent duties of the kind above-mentioned, the Referees have issued two reports, which the Board of Trade have considered of such importance as to be laid before both Houses of Parliament, and thereby made accessible to the public. As the latter of these reports is exciting much attention, we shall devote a few words to one or two of its leading features, especially as it relates to the purification of gas-a matter deeply affecting the sanitary interests of the public.

Every man of science-indeed, any person experienced in the correct processes of investigation-must have been struck with the inadequacy, to use the mildest term, of the evidence adduced before successive Parliamentary Committees on the question of the sulphur-impurity in gas. Indeed, so obviously worthless was this evidence that the Committee of 1868-the last of the series-refused to act upon it, and annulled the decision previously come to in a most hasty and ignorant manner in 1860. As appears from the present report, the Board of Referees have set to work in a very different style. Whatever may have been their opinions at the outset on the results obtained in the laboratory, they rightly considered that the first point to be determined was, what are the actual results of the purify. ing processes employed in the gasworks? With this view, they instituted a uniform and systematic series of experiments, which have been executed under their supervision by the gas engineers of the Companies included under the Acts of 1868-69. The results are of a very startling and extraordinary character.

As the most recent idea, and one held by the highest socalled "authorities" upon the subject, was to trust to the scrubbing processes of purification as the most efficacious for the removal of the sulphur-impurity, the Referees gave their first attention to this point. The results of the experiments, however, showed the utter fallacy of this newest and most hopeful theory. In only one case did the "scrubbers" appreciably diminish the quantity of sulphur in the gas (i.e., the sulphur compounds other than sulphuretted hydrogen), and in the majority of cases it was found that there was actually more sulphur in the gas when it left the scrubbers than when it entered them!

Next, applying their tests to the purifiers, which are expressly employed for the purpose of removing the sulphurimpurity, the Referees again found that the facts were entirely contradictory to the universally received opinion. Their investigations on this point are still incomplete, but they state that in "one of the largest gasworks in London" the result of a month's continuous experiments showed that the gas contained upwards of 30 per cent. more "sulphur" when it left the purifiers than when it entered them! Here is food for reflection with a vengeance. In fine, we make the subjoined excerpt.

"The following is another return, but from a different gaswork, in which all the processes of purification are included:-

\begin{tabular}{|c|c|c|c|c|c|}
\hline & $\begin{array}{l}\text { 1st Expe- } \\
\text { riment. }\end{array}$ & $\begin{array}{l}\text { 2nd Expe- } \\
\text { riment. }\end{array}$ & $\mid \begin{array}{c}\text { 3rd Expe- } \\
\text { riment. }\end{array}$ & $\begin{array}{l}\text { 4th Expe- } \\
\text { riment.* }\end{array}$ & Average. \\
\hline $\begin{array}{l}\text { Inlet of scrubber ... } \\
\text { Outlet of scrubber... }\end{array}$ & $\begin{array}{c}\text { Sulphur. } \\
23 \mathrm{~g}^{\circ} \text {. } \\
24.9\end{array}$ & $\begin{array}{c}\text { Sulphur. } \\
23 \cdot 9 \mathrm{gr} \text {. } \\
22 \cdot 6\end{array}$ & $\begin{array}{l}\text { Sulphur. } \\
25^{\circ} 6 \mathrm{gr}^{\mathrm{r}} \text {. } \\
25^{\circ} 5\end{array}$ & $\begin{array}{c}\text { Sulphur. } \\
25.7 \mathrm{gr} . \\
26.2\end{array}$ & $\begin{array}{l}24.7 \mathrm{gr} . \\
24.8\end{array}$ \\
\hline $\left.\begin{array}{c}\text { Outlet from wet } \\
\text { lime purifier }\end{array}\right\}$ & 2500 & $24: 0$ & $25 \cdot 1$ & $26^{\circ} 3$ & $25^{\circ} 1$ \\
\hline 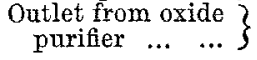 & $21: 1$ & $25 \cdot 2$ & $24 \cdot 6$ & 22. & $24: 0$ \\
\hline
\end{tabular}

* In the 4th set of experiments the gas was passed through dry lime after the oxide.

"In this case the effects of the purifying processes are actually nil, the gas having passed through all stages of purification, without any diminution of its sulphurimpurity."

The Referees suggest what appears to be a correct chemical explanation of the unexpected fact of more sulphur being found in the gas at the outlet of the scrubbers than at the inlet; but they offer no suggestion in regard to the still more extraordinary fact of the same kind obtained from the "purifiers." They state that their investigations are still being carried on, and, unquestionably, the great desideratum is an accurate knowledge of the facts. Facts are the first things to be looked to; it will be time enough to theorise when the data of theory are before us. But the thought that must suggest itself to everyone is,-How is it that such a state of matters exists? Still more,-How 